\title{
Direct powder forging of PM nickel-based superalloy: densification and recrystallisation
}

\author{
Shuyun Wang ${ }^{1,2} \cdot$ Shuang Fang ${ }^{1,2} \cdot$ Zhusheng Shi $^{2} \cdot$ Jiaying Jiang $^{2} \cdot$ Xiaoming Zhou $^{1,2}$. \\ Jianguo Lin ${ }^{2}$
}

Received: 21 April 2016/Accepted: 23 May 2016/Published online: 6 June 2016

(C) The Author(s) 2016. This article is published with open access at Springerlink.com

\begin{abstract}
Powder metallurgy nickel-based superalloys have been widely used in high temperature applications. For these materials, a fully dense and fine-grained microstructure is important. Full densification can be achieved by a suitable processing technique, while the latter can be achieved through recrystallisation for which valuable guidance is provided by the information about recrystallisation nuclei. In this study, a fully dense powder metallurgy nickel-based superalloy component has been produced by a new manufacturing methoddirect powder forging - using a single acting hydraulic press under normal atmosphere. Boundary misorientation of the produced material has been analysed to determine the degree of recrystallisation nucleation. A finite element model for direct powder forging has been developed in DEFORM-2D/3D and validated by comparing experimental and simulated load curves. The relationship of stress and strain state with densification and recrystallisation nucleation degree has been analysed. It was found that the direct powder forged FGH96 alloy has a much higher recystallisation nucleation degree and more recrystallised sub-grains, compared with those of the hot isostatic pressed material. Within the forged component, a higher recystallisation nucleation degree resides in the material near the container wall where greater values of shear strain rate have operated.
\end{abstract}

Keywords Direct powder forging $\cdot$ PM nickel-based superalloy $\cdot$ Finite element modelling $\cdot$ Fully dense component $\cdot$ Densification $\cdot$ Recrystallisation

Zhusheng Shi

zhusheng.shi@imperial.ac.uk

$1 \quad$ Beijing Institute of Aeronautical Materials, Beijing 100095, China

2 Department of Mechanical Engineering, Imperial College London, London SW7 2AZ, UK

\section{Introduction}

High temperature structural components are important members in advanced gas turbine engines and require excellent high temperature mechanical properties such as ultimate tensile strength and fatigue resistance, as they operate at high temperature and are highly stressed. Precipitation-hardened nickel-based superalloy has been widely used for structural parts in gas turbine engine applications for more than 50 years [1-3], and the demand for improved engine efficiency and higher performance has resulted in continual development of high strength polycrystalline superalloy $[4,5]$. Powder metallurgy (PM) technology was introduced to overcome the severe segregation that often arose in processing bulk material, as PM processing can produce a fine, homogeneous and macrosegregation-free structure. During hot working of PM nickel-based superalloy, recrystallisation refines the grain structure which results in improved mechanical properties $[2,6]$.

The main production methods for PM nickel-based superalloy include hot isostatic pressing (HIP) [7], direct hot extrusion, HIP + forging [8], hot extrusion + forging [9], HIP + heat treatment $[10,11]$ and HIP + hot extrusion. The most commonly used method is HIP since this technique has an immense potential for producing near net-shaped components with near theoretical full density [12-14]. Nickel-based superalloy produced by HIP has highly homogeneous structure containing fine grains, annealing twins and prior particle boundaries (PPBs) decorated with the stable oxides $\left(\mathrm{Al}_{2} \mathrm{O}_{3}\right.$ and $\left.\mathrm{TiO}_{2}\right)$ as well as brittle $\mathrm{MC}(\mathrm{Nb}, \mathrm{Ti}) \mathrm{C}$ carbides $[15,16]$. Subsequent hot extrusion or forging may break and disperse the PPBs because of dynamic recrystallisation (DRX) which occurs when deformation is large enough. Figure 1 shows a nickel-based superalloy powder ingot for HIP process, and the HIPed component as well as its corresponding microstructure. The analysis of the misorientation 
(a)
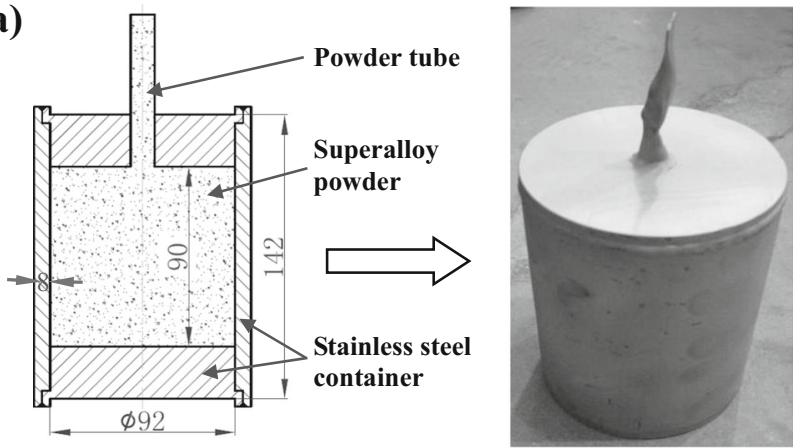

(b)
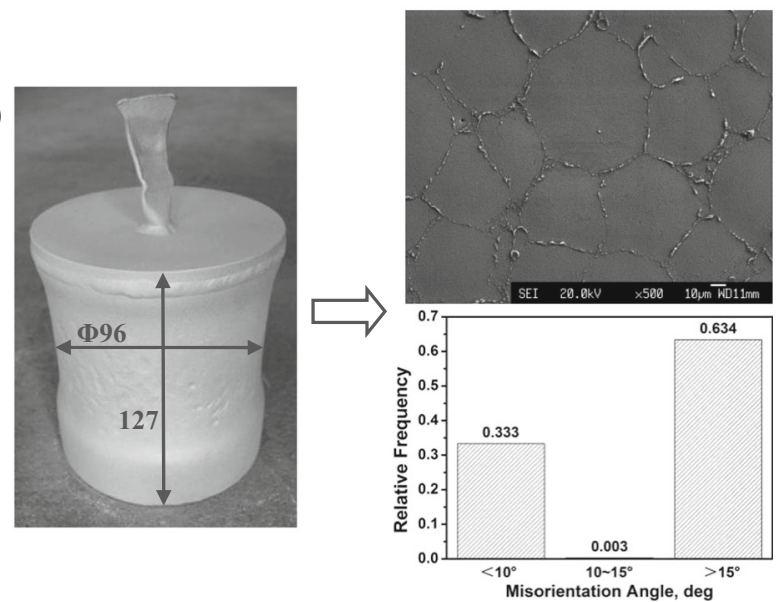

Fig. 1 a Powder ingot for commonly used powder consolidation technique. b HIPed FGH96 alloy component with microstructure and grain boundary misorientation analysis (dimensions in $\mathrm{mm}$ ) constitution of grain boundaries shows that the microstructure contains some dynamically recrystallised nuclei $\left(<10^{\circ}\right)$ and a large number of large-angle grain boundaries $\left(>15^{\circ}\right)$ representing PPBs which can be seen clearly from SEM image in Fig. 1.

Recently, a new processing method, direct powder forging technique, has been reported $[17,18]$ which was conducted in normal atmosphere. With a very simple experimental setup (flat upsetting tools), full density was achieved in the central part of the powder ingot. The PM nickel-based superalloy produced by this technique resulted in a significant improvement of microstructure, such as recrystallised structure and dispersed PPBs, compared with hot isostatic pressing. However, the forming rate used in the study was $200 \mathrm{~mm} / \mathrm{s}$, which may not be readily available for large tonnage hydraulic machines used for the production of large components. The low cost and high productivity feature of this technique, coupled with the potential for improved microstructure, necessitates further investigation of this method for the production of fully dense components, particularly for forming rates attainable with common machines.

In this study, a PM nickel-based superalloy component has been produced by the direct powder forging technique, using a single-acting hydraulic machine in normal atmosphere. Experimental setup was modified with the tooling shown later in Fig. 2a to ensure densification of the powder material. The density and boundary misorientation of the produced powder ingot have been investigated. A finite element model for direct powder forging has been developed in DEFORM-2D/3D to
Fig. 2 Experimental setup for the direct powder forging process: a powder billet geometry (dimensions in $\mathrm{mm}$ ) and protective covers and $\mathbf{b}$ direct powder forging equipment, tooling and setup

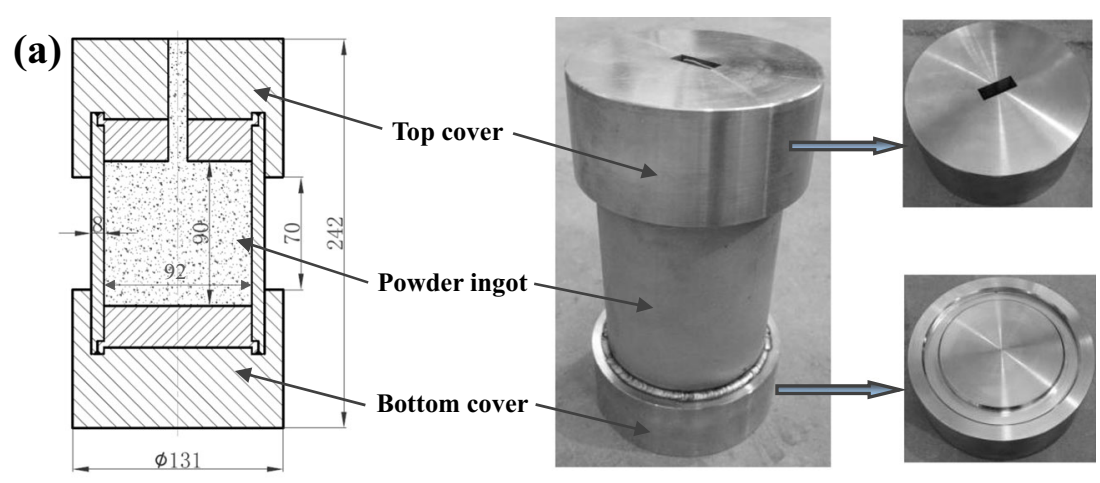

(b)

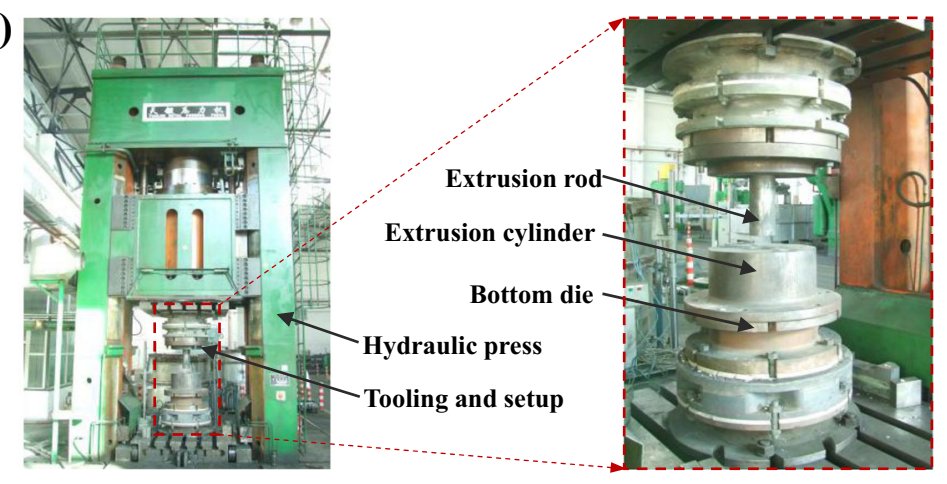


Table 1 Chemical composition of FGH96 alloy

\begin{tabular}{lllllllll}
\hline Element & $\mathrm{Cr}$ & $\mathrm{Co}$ & $\mathrm{Mo}$ & $\mathrm{W}$ & $\mathrm{Ti}$ & $\mathrm{Al}$ & $\mathrm{C}$ & $\mathrm{Ni}$ \\
\hline $\begin{array}{c}\text { Content, } \\
\text { wt } \%\end{array}$ & 15.94 & 12.90 & 4.10 & 4.00 & 3.62 & 2.22 & 0.042 & Remaining \\
\hline
\end{tabular}

investigate the relation of stress and strain distribution with densification and recrystallisation.

\section{Experimental setup and method}

Argon atomised FGH96 powder with an average particle size of $30 \mu \mathrm{m}$ was supplied by Beijing Institute of Aeronautical Materials (BIAM). FGH96 alloy is a PM nickel-based superalloy, similar to Rene 88DT. Its chemical composition is shown in Table 1.

The powder particles were poured into a cylindrical container of stainless steel AISI 304 which was evacuated of air to a pressure of less than $1.0 \times 10^{-5} \mathrm{~Pa}$ and the container sealed, in order to avoid oxidation of the powder at high temperature. For consistency of the initial powder ingot conditions, the dimensions of the container used were the same as that shown in Fig. 1a. The powder filling tube does not affect deformation in hot isostatic pressing process, but will have some effect on the direct powder forging process. Previously [17, 18], the powder ingot was placed horizontally, and fully dense material was obtained only in the central part of the ingot. In an attempt to obtain a fully dense PM superalloy component with recrystallised microstructure, the container was redesigned with top and bottom covers, as shown in Fig. 2. The top cover protects the powder filling tube from deformation and keeps the ingot temperature more stable for deformation, and the bottom cover ensures container stability. The protective covers were also manufactured from stainless steel AISI 304. The geometry of the powder billet, consisting of powder ingot and top and bottom protective covers, is shown in Fig. 2a. The total height of the billet was $242 \mathrm{~mm}$, and the maximum diameter of the end covers was $131 \mathrm{~mm}$, which was larger than the diameter of the powder ingot to allow some radial flow. On the other hand, the extrusion cylinder, whose inner diameter is the same as the maximum diameter of the end covers, sets a limit for the radial expansion and imposes a radial stress towards the centre on the powder during forging. The billet was coated with glass lubricant on its outside surface to reduce friction during deformation.
Figure $2 \mathrm{~b}$ shows the direct powder forging equipment and the tooling and setup. The equipment is a single-acting hydraulic press with a load capacity of $20,000 \mathrm{kN}$ and a maximum speed of $20 \mathrm{~mm} / \mathrm{s}$. The tooling includes an extrusion cylinder fitted with an extrusion rod and a bottom die blocking the exit, and was manufactured from H13 steel. The servo-hydraulic machine was connected to an oscilloscope to record load and stroke during the forging process.

The powder billet was heated in a furnace to $1070{ }^{\circ} \mathrm{C}$, the usual deformation temperature for the FGH96 alloy [19, 20], and soaked for $2 \mathrm{~h}$ to achieve uniform temperature distribution. Then the powder billet was transferred into the tooling within $40 \mathrm{~s}$ and was forged at a speed of $17 \mathrm{~mm} / \mathrm{s}$ to the final shape. The whole process was carried out in normal atmosphere, and the total time for the direct forging period was $2.1 \mathrm{~s}$.

Electron backscatter diffraction (EBSD) was used to characterise the grain boundary misorientation of the material. The samples for different locations (shown later in Fig. 5) were longitudinally sectioned, mounted, mechanically polished and then electrolytically polished in corrosive solution of methanol and sulfuric acid (4:1 in volume). EBSD study was conducted on a FE-SEM scanning electron microscope equipped with HKL Channel 5 software, with a step size of $1.2 \mu \mathrm{m}$ and an operating voltage of $20 \mathrm{kV}$. The density of all samples was measured using Archimedes drainage method.

\section{Numerical modelling}

\subsection{Material model}

Deformation behaviour has often been studied using FEM with constitutive equations [21]. Both internal variable and state variable models of flow stress have been used in forging process modelling [22]. In this study, a viscoplastic constitutive model from [23] was employed. The thermo-mechanical characteristics of FGH96 alloy were measured from compression test for the fully dense HIPed material. The material constants were determined from the experimental stress-strain results. The constitutive equations for the high-temperature flow stress during work hardening, dynamic recovery and dynamic softening stages for the Ni-based superalloy can be summarised as follows:

$$
\begin{aligned}
& \sigma=\sigma_{p}\left\{1-\frac{2}{1.014 \pi} \arcsin \left\{\exp \left(\frac{-1.014 \pi c \varepsilon f_{0}}{2 \sigma_{p}}\right) \times \sin \left[\frac{1.014 \pi}{2}\left(1-\frac{c s_{0}}{\sigma_{p}}\right)\right]\right\}\right\}\left(\text { when } \sigma \leq \sigma_{p}\right) \\
& \sigma=\sigma_{p}\left[\frac{\varepsilon}{\varepsilon_{p}} \exp \left(1-\frac{\varepsilon}{\varepsilon_{p}}\right)\right]^{c_{1}}\left(\text { when } \sigma>\sigma_{p}\right)
\end{aligned}
$$


$\sigma_{p}=3.014 \times 10^{-4}\left(\frac{Z}{4.16 \times 10^{9}}\right)^{-0.064}\left[\ln \left(\frac{Z}{4.16 \times 10^{9}}\right)\right]^{\frac{1}{0.204}}$

$f_{0}=184.98 Z^{-0.271}$

$c=\left[\ln \left(\frac{Z}{4.16 \times 10^{9}}\right)\right]^{\frac{1}{0.204}}$

$\varepsilon_{p}=0.006 Z^{0.0814}$

$c_{1}=0.0114 Z^{0.0514}$

$Z=\dot{\varepsilon} \exp \left(\frac{444.773}{R T}\right)$

$s_{0}=-0.214+6.740 \times 10^{-4} \times T-8.042 \times 10^{-7} \times T^{2}$

$$
+4.416 \times 10^{-10} \times T^{3}-8.271 \times 10^{-14} \times T^{4}
$$

Where $\sigma$ and $\sigma_{p}$ represent the flow stress and the peak stress, respectively, $\varepsilon_{p}$ represents the peak strain, $Z$ is the Zener-Hollomon parameter, $c, c_{1}$ and $f_{0}$ are material constants for a given strain rate and the deformation temperature and $s_{0}$ is the initial value for a given deformation temperature.

The material used for the container and the top and bottom covers was stainless steel AISI 304 and the tooling was steel AISI H13. The material models for stainless steel AISI 304 and steel AISI H13 were from materials database of commercial finite element software DEFORM-2D/3D.

\subsection{Finite element model}

A 2D finite element (FE) model was employed because of the axial symmetry. Figure 3a shows the geometry of the finite element model of the direct powder forging set-up. The FE (a)

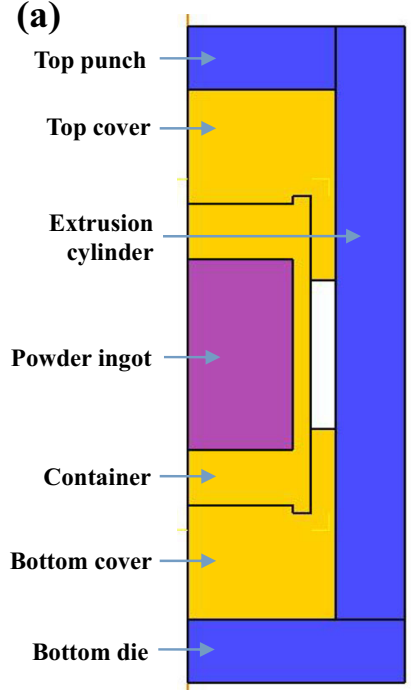

(b)

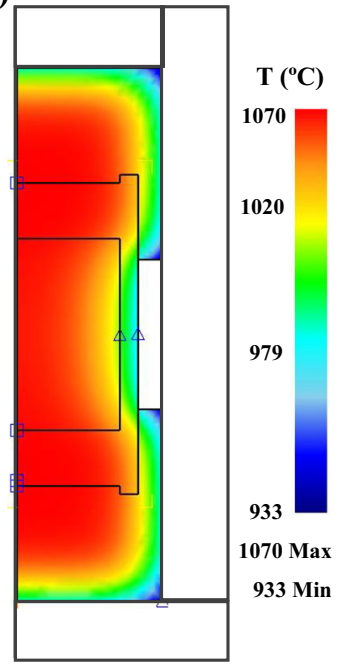

Fig. 3 a Geometric model and $\mathbf{b}$ thermal analysis result just before the start of direct forging process (after $40 \mathrm{~s}$ transfer period) model had seven objects. The powder billet, which included the powder ingot and the top and bottom covers, was considered as a deformable body and the die set, which consisted of the top punch (the extrusion rod), the bottom die and the extrusion cylinder, was considered as a rigid body in the simulation process. It is noted that the powder tube of the billet has been omitted in the geometry model for simplicity, and its influence on the process is expected to be minor from experience.

The whole forging process was simulated using de-coupled thermal and mechanical modelling. First, heat transfer analysis was performed to simulate the temperature drop during transfer of the powder billet from furnace to tooling, using DEFORM-2D/Standard. During heat transfer analysis, fixed boundary conditions were defined on the outer surface of the powder billet, and a heat transfer with the environment was defined for all the surfaces. The thermal conductivities of FGH96 alloy and steels were set to a constant value 28.75 and $22 \mathrm{~W} / \mathrm{mK}$, respectively [2]. The temperature distribution of the powder billet just before the start of direct forging (after the $40 \mathrm{~s}$ transfer period) is shown in Fig. 3b. The temperature field was then imported into the FE model. The initial temperature and the number of elements of the model objects are presented in Table 2.

DEFORM-2D/3D provides a facility to treat the powder as a continuum and output the relative density. An initial relative density of 0.7 was assigned to the powder for forging simulation. At this stage, the temperature change in the powder billet and the die set was ignored due to short forging time. The unified viscoplastic constitutive equations were integrated in DEFORM-2D/3D via a user-defined subroutine. The velocity of the top punch was defined as $17 \mathrm{~mm} / \mathrm{s}$, the same speed as that used in the current direct powder forging experiment. The friction coefficient at the contact interface between the tooling and the powder billet was an important parameter to define and was directly dependent on the temperature and lubricant. The values of the two friction coefficients were determined through parametric studies for obtaining a close fit between the experimental and predicted forging load curves, as shown in Fig. 4. A friction coefficient of 0.3 was used between the

Table 2 Initial temperature and number of elements of the model objects

\begin{tabular}{lll}
\hline Objects & Initial temperature, ${ }^{\circ} \mathrm{C}$ & Number of elements \\
\hline Powder ingot & $1022-1070$ & 2213 \\
Container & $983-1070$ & 4595 \\
Top cover & $933-1070$ & 363 \\
Bottom cover & $933-1070$ & 396 \\
Extrusion cylinder & 400 & 100 \\
Top punch & 20 & 66 \\
Bottom die & 20 & 60 \\
\hline
\end{tabular}




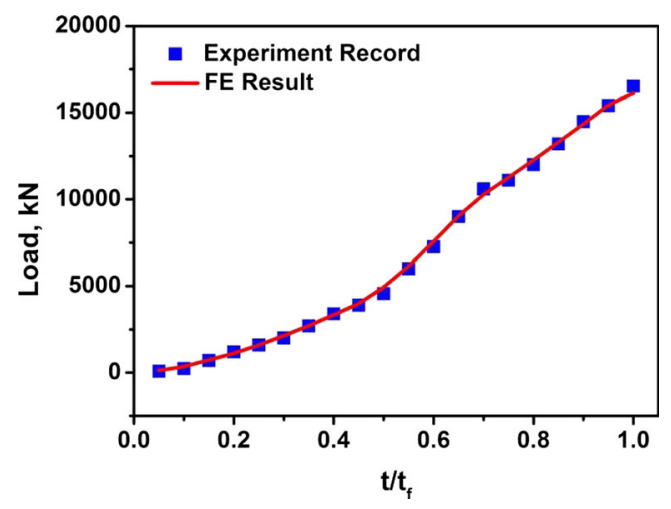

Fig. 4 Comparison of experiment record (symbols) and FE result (solid line) for load variation with time during direct forging process

tooling and the powder billet, which is in the range for heavy forging process $[17,21]$, and a friction coefficient of 0.7 was used at the contact interface between the powder and the container which was without lubrication.

The simulated downward thrust force against the top punch was compared with the experimentally measured force. The average force after tooling engagement was calculated and plotted in Fig. 4. It can be seen from Fig. 4 that experimental and FE simulation results are in a good agreement. The load increases gradually with the increasing time, and a maximum load of $17,000 \mathrm{kN}$ was reached at the end of forging process.

\section{Results and discussion}

\subsection{Densification and stress distribution}

Figure 5 shows the longitudinal section of the powder billet after forging. Because of the protection of top and bottom covers, the powder tube was not damaged, indicating that probably, a vacuum had been maintained in the capsule during forging. Distortion of top and bottom covers was small. However, because of the gap between the container and the inner wall of the extrusion cylinder, and the higher temperature of container and powder particles than the top punch and the bottom die, the side of the container flowed into the gap forming a flange at mid height. As a result, a certain degree of radial flow was achieved for the powder particles.

The minimum requirement in the hot forming of powder material is densification of the particles. Thirty samples $(10 \times 10 \times 10 \mathrm{~mm})$ were cut in the longitudinal section of the powder ingot and sequentially numbered (no. 1 to no. 30 ), as shown in Fig. 5. The experimentally measured density of all the samples from the powder forging was between 8.341 and $8.348 \mathrm{~g} / \mathrm{cm}^{3}$, achieving the theoretical density of the alloy. Some feature samples covering most regions of the powder ingot and located in the horizontal centre line (nos. 3, 8, 18 and 28) and both top and bottom lines (nos. 16, 26, 20 and 30) were selected for further analysis.

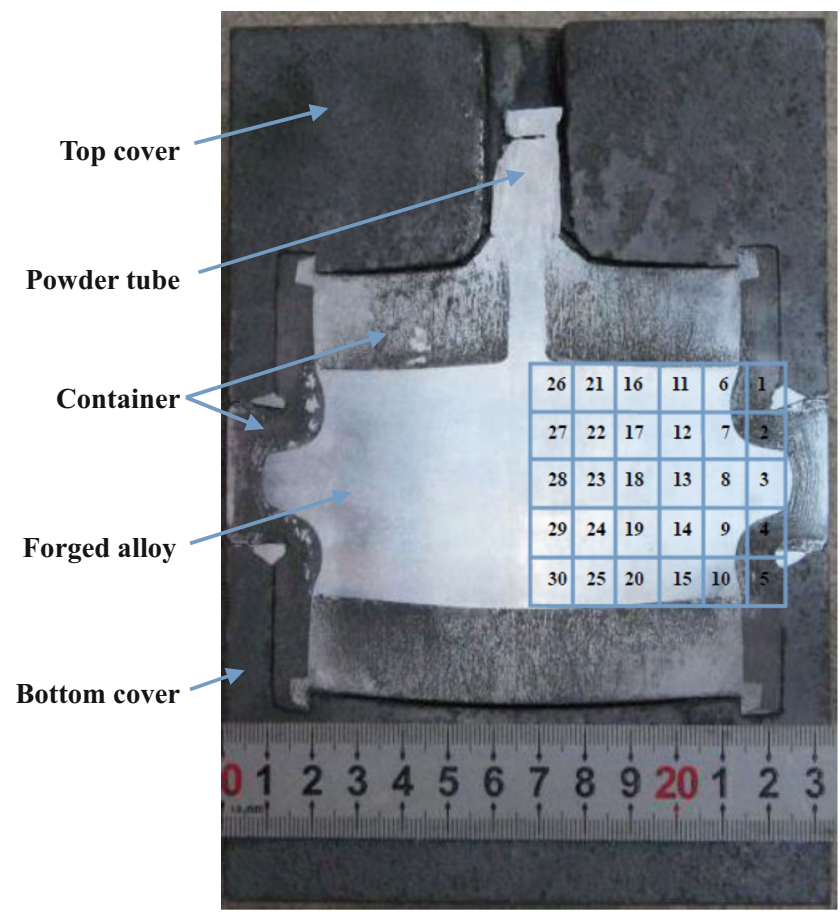

Fig. 5 A longitudinal section of forged powder billet and location of samples

Figure 6 shows the simulated evolution of relative density with time. Each curve represents the result of the centre location of the corresponding sample in the FE model described above and is labelled with prefix L. It can be seen that the densification trends for different locations had some difference, but they all reached almost the same relative density at $t / t_{f}=0.95$ and full densification at the end of the process. The relative density of sample 18 and sample 28 , located in the horizontal centre line and away from the container, increased rapidly up to $t / t_{f}=0.7$ and then increased more slowly, while the relative density of samples 3, 16, 20, 26 and 30, located near the container wall, increased slowly before $t / t_{f}=0.6$ and then increased rapidly. The relative density of sample 8 , which sits on the horizontal centre line but not far from the container, was between the two trends mentioned above. The reason for

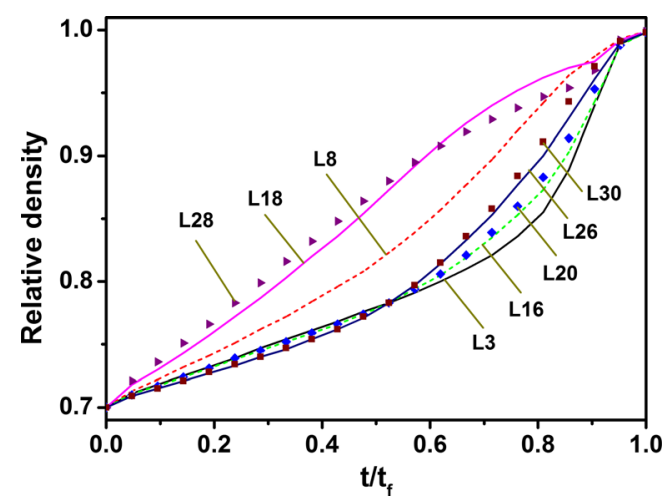

Fig. 6 Evolution of simulated relative density during direct powder forging process 
the different behaviour is due to the different stress state at these locations, which will be discussed later. It is noted that the behaviour of L16 and L20 is very similar, which is to be expected because of their similar but opposite location relative to their neighbours. Similar behaviour was also observed for L26 and L30.

The predicted final relative density in Fig. 6 is in agreement with the experimentally measured values. Together with the good consistency of the experimentally measured force and the FE simulated force, it can therefore be assumed that the FE model developed in this paper is representative of the direct powder forging process and could be used to predict the relative density distribution of forged powder ingot produced by the process.

Figure 7 shows the evolution of effective stress and mean stress of the indicated locations as well as their distribution at different times. The effective stress ( $\left.\sigma_{\text {Effective }}\right)$ and the mean stress $\left(\sigma_{\text {Mean }}\right)$ are calculated according to the following equations:

$\sigma_{\text {Effective }}=\frac{1}{\sqrt{2}} \sqrt{\left(\sigma_{x}-\sigma_{y}\right)^{2}+\left(\sigma_{y}-\sigma_{\theta}\right)^{2}+\left(\sigma_{\theta}-\sigma_{\mathrm{x}}\right)^{2}+6\left(\tau_{x y}{ }^{2}+\tau_{y \theta}{ }^{2}+\tau_{\mathrm{x} \theta}{ }^{2}\right)}$

$\sigma_{\text {Mean }}=\frac{\sigma_{\max }+\sigma_{\min }}{2}$
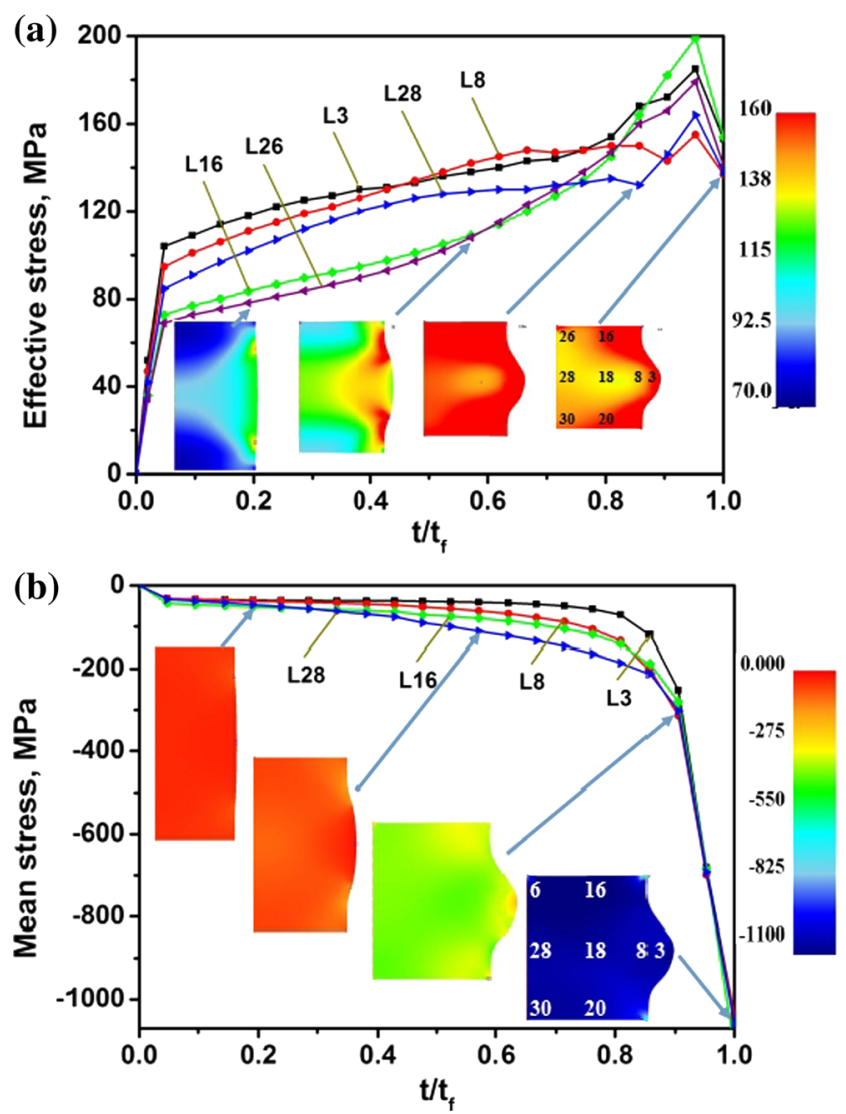

Fig. 7 Simulated evolution of $\mathbf{a}$ effective stress and $\mathbf{b}$ mean stress during direct forging process where $\sigma_{x}, \sigma_{y}$ and $\sigma_{\theta}$ are the stress components along radial, height and azimuthal directions respectively, $\tau_{\mathrm{xy} y} \tau_{\mathrm{y} \theta}$ and $\tau_{\mathrm{x} \theta}$ are the shear stresses and $\sigma_{\max }$ and $\sigma_{\min }$ are the maximum and the minimum of the principal stresses. In the present study, $\sigma_{\theta}=\sigma_{x}, \tau_{y \theta}=\tau_{\mathrm{x} \theta}=0$.

As shown in Fig. 7a, the samples located on the horizontal centre line and the samples at both top and bottom lines of powder ingot displayed two different trends for effective stress. The effective stresses at samples on the horizontal centre line increased to between 80 and $100 \mathrm{MPa}$ very quickly and then increased slowly. The effective stresses at top and bottom lines reached about $70 \mathrm{MPa}$ initially and then increased slowly at first then with an accelerated increasing rate until $t / t_{f}=0.95$. After $t / t_{f}=0.95$, the effective stresses started to decrease when the relative density at all locations reached a value close to 1 (see Fig. 6), and the differences between normal stress components became small. Figure $7 \mathrm{~b}$ shows the evolution and distribution of the mean stress. The negative value of the mean stress of all samples during the whole period indicates consolidation and pore closure process, and the dramatic increase in the magnitude of the mean stress after $t / t_{f}=0.9$ is an indication that the powder compact was close to full density and had much stronger resistance to further consolidation.

Figure 8 shows the Evolution of $\sigma_{x}, \sigma_{y}, \tau_{x y}$ and the stress triaxiality of different locations of the powder ingot during direct forging process. Due to the designed gap between the powder ingot and the external cylinder, radial flow into a flange occurred. Initially, there was little resistance to radial flow at Samples 3 and 8. Therefore, Samples 3 and 8, especially Sample 3, had very low magnitude of $\sigma_{x}$ during the majority part of the forming process. However, Sample 3 showed markedly faster increase than other samples in the magnitude of $\sigma_{x}$ from around $t / t_{f}=0.85$, probably because the container had come into contact with the internal wall of the extrusion cylinder. The trend of $\tau_{x y}$ for all the samples were different, but in general $\tau_{x y}$ in the corresponding samples at the top and bottom lines showed similar magnitude with opposite sign because of the outward flow of loose powder near the centre line towards the cylinder. The stress triaxiality of all the samples remained negative during deformation, so pore closure would be promoted [24-26]. Further work will be needed to quantify the relation between stress state, density and microstructure.

\subsection{Recrystallisation and Strain Distribution}

The second requirement in the forming of the powder material is to acquire a fine and recrystallised structure [27, 28]. Figure 9 shows EBSD results of the grain boundary misorientation for different samples of the directly forged powder ingot. Compared with the results for HIPed material in Fig. 1b, 
Fig. 8 Evolution of $\sigma_{x}, \sigma_{y}, \tau_{x y}$ and stress triaxiality of the powder ingot during direct forging process
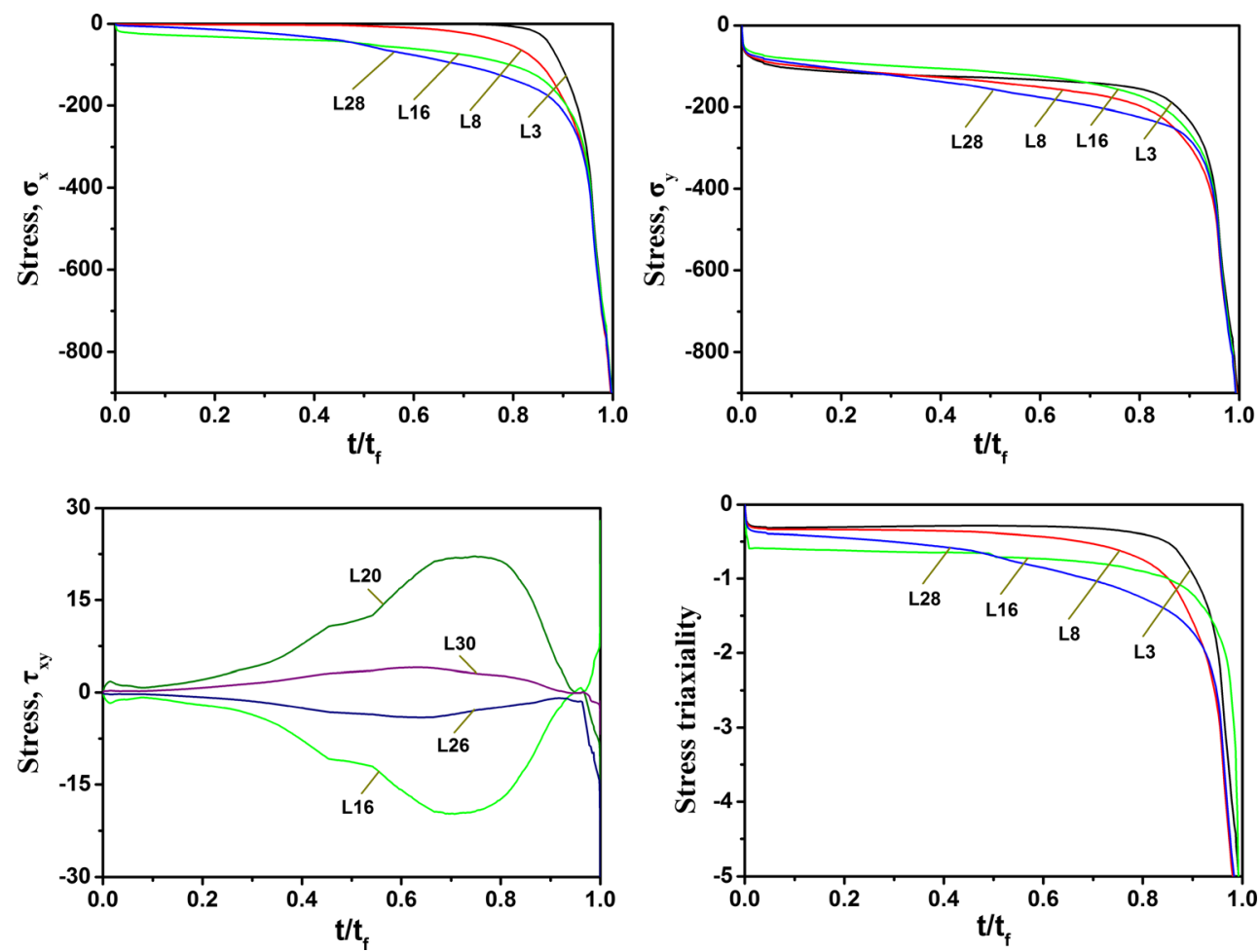

the relative frequencies for boundary misorientation of $<10^{\circ}$ and $10-15^{\circ}$ had a substantial increase in direct powder forged samples while that for $>15^{\circ}$ had a marked drop. Boundary misorientation $<10^{\circ}$ represents recrystallisation nucleation degree and that of $10-15^{\circ}$ represents sub-grains which have undergone recrystallisation, while boundary misorientation $>15^{\circ}$ indicates a large-angle boundary with PPBs. Therefore the current results show that the direct powder forged material has a much stronger tendency to recrystallisation than HIPed material. Among different locations of the direct forged ingot, samples near the container (No. 3, 16, 20, 26 and 30) had higher relative frequencies for boundary misorientation of $<10^{\circ}$ indicating that these samples may have some favourable conditions for the driving force of recrystallisation nucleation. On the other hand, samples in the central part (No. 8, 18 and 28) had slightly higher relative frequencies for boundary misorientation of $10-15^{\circ}$, indicating more recrystallised sub- grains. So it could be conjectured that the accumulated strain energy was lower in these samples. During subsequent heat treatment these samples may not have sufficient energy for recrystallisation nucleation and may induce abnormal grain growth [6, 29, 30].

Recrystallisation nucleation occurs when a certain strain amount requirement is met. Figure 10 shows the evolution and distribution of effective strain for different locations of the powder ingot. The effective strain $\left(\varepsilon_{\text {Effective }}\right)$ is calculated according to the following equation:

$$
\varepsilon_{\text {Effective }}=\frac{\sqrt{2}}{3} \sqrt{\left(\varepsilon_{x}-\varepsilon_{y}\right)^{2}+\left(\varepsilon_{y}-\varepsilon_{\theta}\right)^{2}+\left(\varepsilon_{\theta}-\varepsilon_{\mathrm{x}}\right)^{2}+6\left(\gamma_{x y}{ }^{2}+\gamma_{y \theta}{ }^{2}+\gamma_{x \theta}{ }^{2}\right)}
$$

where $\varepsilon_{x}, \varepsilon_{y}$ and $\varepsilon_{\theta}$ are the strain components along radial, height and azimuthal directions respectively, $\gamma_{\mathrm{x} y}, \gamma_{\mathrm{y} \theta}$ and
Fig. 9 Relative frequency of grain boundary misorientation angle for samples of the powder ingot after direct forging

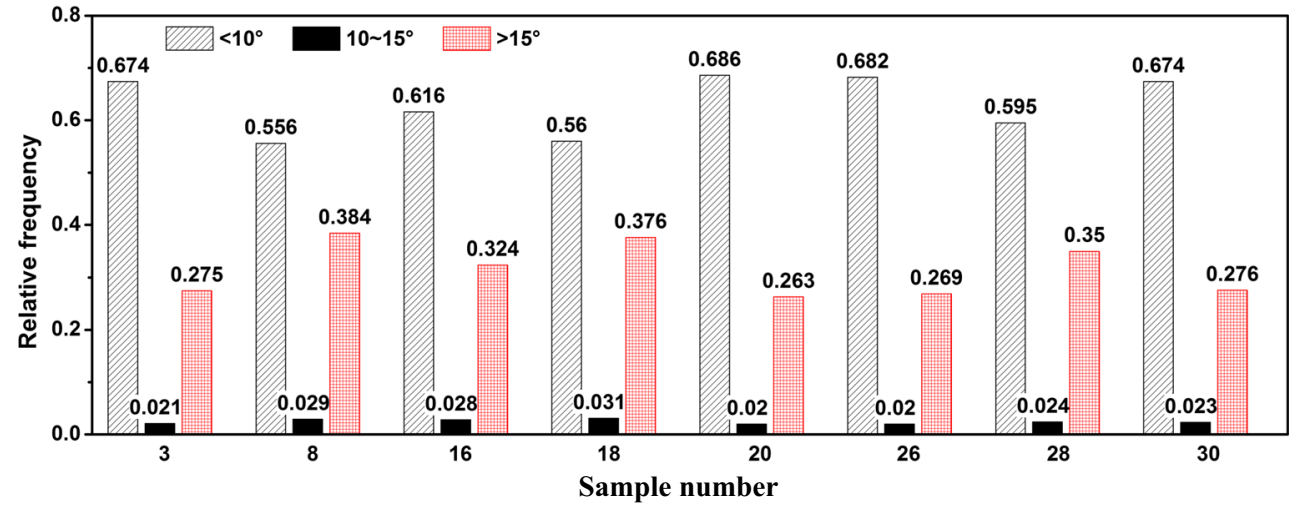




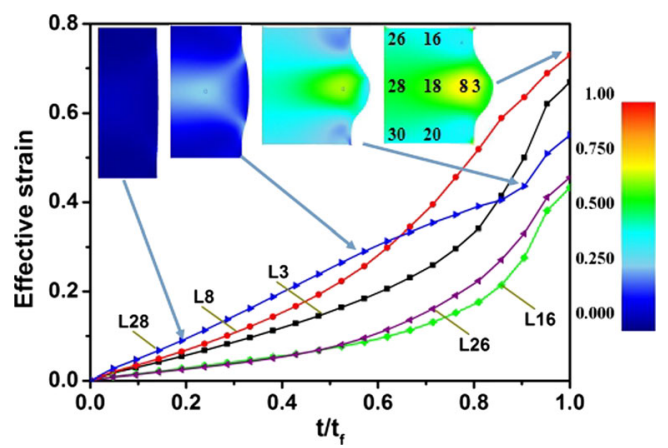

Fig. 10 Evolution and distribution of effective strain during direct powder forging process

$\gamma_{\mathrm{x} \theta}$ are the shear strains. In the present study, $\varepsilon_{\theta}=\varepsilon_{x}$, $\gamma_{y \theta}=\gamma_{x \theta}=0$.

During the forming process, the effective strain of all the samples increased gradually and continuously. Samples 8, 18 and 28 in the central part increased more rapidly and had higher final effective strain values. However, a lower recrystallisation nucleation degree was observed in these regions. Nevertheless, slightly higher relative frequencies for boundary misorientation of $10-15^{\circ}$ occurred in these regions, indicating that some recrystallisation nuclei had grown to subgrains because of their higher effective strain throughout the process. Samples at the top and bottom lines (No. 16, 20, 26 and 30) had lower effective strain but higher recrystallisation nucleation degree, which could be related to their rapid increase in effective strain in the later stage of the process. On the other hand, Sample 3 had high final effective strain and high recrystallisation nucleation degree. These results show that the final effective strain is not a sufficient condition for recrystallisation nucleation which is related with the rate of strain accumulation [31, 32].

Many researchers have reported the importance of $\gamma_{x y}$ for the recrystallisation behaviour [33, 34]. Figure 11 shows the evolution of $\varepsilon_{x}, \varepsilon_{y}$ and $\gamma_{x y}$ for the feature samples of the powder ingot. The samples can be divided into two groups according to their $\varepsilon_{x}$ and $\varepsilon_{y}$ behaviour: the samples located in the horizontal centre line and the samples at the top and bottom lines. Samples 3, 8, 18 and 28 located in the horizontal centre line had higher magnitudes of $\varepsilon_{x}$ and $\varepsilon_{y}$ than samples at the top and bottom lines, but their recrystallisation nucleation degree was not always higher, as presented earlier. Sample 3 had higher $\varepsilon_{x}$ and $\varepsilon_{y}$, and also higher recrystallisation nucleation degree. There was negligible change of $\varepsilon_{x}$ for Sample 3 from $t / t_{f}=0.9$ onwards, possibly because the gap between the container and the extrusion cylinder had been filled and the radial movement had been blocked. Meanwhile, $\sigma_{x}$ for Sample 3 increased dramatically from this time as shown in Fig. 8. Also from $t / t_{f}=0.9$, there were marked changes in the evolution of $\gamma_{x y}$ for the outer samples of the powder ingot (samples $3,8,16$ and 20).

Based on the results presented above, the whole deformation process may be divided into two stages by $t / t_{f}=0.9$. Table 3 shows the values of $\varepsilon_{x}, \varepsilon_{y}$ and $\gamma_{x y}$ as well as the strain rates for all the feature samples of the powder ingot for the two
Fig. 11 Evolution of $\varepsilon_{x}, \varepsilon_{y}$ and $\gamma_{x y}$ of the indicated samples of the powder ingot during direct forging process
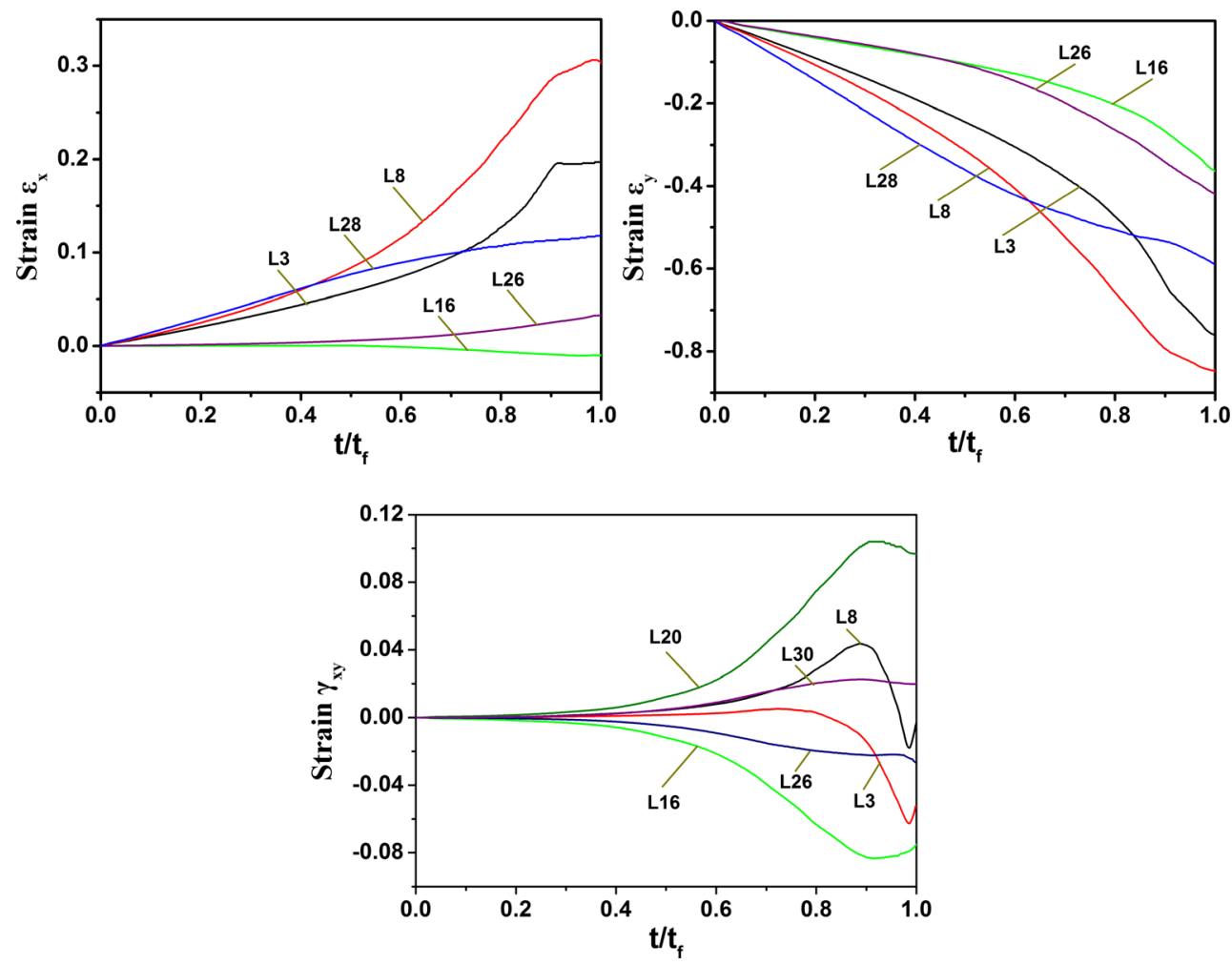
Table $3 \varepsilon_{x}, \varepsilon_{y}$ and $\gamma_{x y}$ and their strain rates for each sample of the powder ingot

\begin{tabular}{|c|c|c|c|c|c|c|c|}
\hline$\Delta t(\mathrm{~s})$ & Sample & $\left|\Delta \varepsilon_{x}\right|$ & $\dot{\varepsilon}_{x}\left(\mathrm{~s}^{-1}\right)$ & $\left|\Delta \varepsilon_{y}\right|$ & $\dot{\varepsilon}_{y}\left(\mathrm{~s}^{-1}\right)$ & $\left|\Delta \gamma_{x y}\right|$ & $\dot{\gamma}_{x y}\left(\mathrm{~s}^{-1}\right)$ \\
\hline \multirow[t]{8}{*}{1.89} & 3 & 0.190 & 0.101 & 0.639 & 0.338 & 0.043 & 0.023 \\
\hline & 8 & 0.285 & 0.151 & 0.794 & 0.420 & 0.015 & 0.008 \\
\hline & 16 & 0.009 & 0.005 & 0.268 & 0.142 & 0.083 & 0.044 \\
\hline & 18 & 0.195 & 0.103 & 0.658 & 0.348 & 0.016 & 0.008 \\
\hline & 20 & 0.004 & 0.002 & 0.293 & 0.155 & 0.103 & 0.054 \\
\hline & 26 & 0.025 & 0.013 & 0.343 & 0.181 & 0.022 & 0.012 \\
\hline & 28 & 0.113 & 0.060 & 0.535 & 0.283 & 0.003 & 0.002 \\
\hline & 30 & 0.034 & 0.018 & 0.375 & 0.198 & 0.026 & 0.014 \\
\hline \multirow[t]{8}{*}{0.21} & 3 & 0.001 & 0.005 & 0.107 & 0.510 & 0.039 & 0.186 \\
\hline & 8 & 0.017 & 0.081 & 0.050 & 0.238 & 0.037 & 0.176 \\
\hline & 16 & 0.001 & 0.005 & 0.096 & 0.457 & 0.007 & 0.033 \\
\hline & 18 & 0.004 & 0.019 & 0.026 & 0.124 & 0.017 & 0.081 \\
\hline & 20 & 0.001 & 0.005 & 0.094 & 0.448 & 0.006 & 0.029 \\
\hline & 26 & 0.008 & 0.038 & 0.074 & 0.352 & 0.005 & 0.024 \\
\hline & 28 & 0.005 & 0.024 & 0.054 & 0.257 & 0.003 & 0.014 \\
\hline & 30 & 0.008 & 0.038 & 0.064 & 0.305 & 0.005 & 0.024 \\
\hline
\end{tabular}

Notes Bold is used for samples near container wall $(3,16,20,26,30)$

stages. In the first stage, the strain rates of $\gamma_{x y}$ for samples 3 , $16,20,26$ and 30 near the container wall were all greater than $0.01 \mathrm{~s}^{-1}$ and they had higher recrystallisation nucleation degree. It is also noticed that for these samples except sample 3, the $\gamma_{x y}$ values were greater than $\varepsilon_{x}$. For sample 3 , the value of $\gamma_{x y}$ was less than the $\varepsilon_{x}$ since the gap between the container and the inner wall of the extrusion cylinder allowed more radial movement of sample 3 with low magnitude of $\sigma_{x}$. In the second stage with very short time interval, no regular pattern has been found.

In summary, recrystallisation has a complicated relationship with the strain. It appears that samples with higher effective strain increment rate at later stage of the process and with shear strain rate greater than $0.01 \mathrm{~s}^{-1}$ have higher recrystallisation nucleation degree. Other factors particularly temperature will have an effect on recrystallisation, but it is beyond the scope of the current study since a stable temperature field is assumed during the rapid forging process.

\section{Conclusions}

In this study, a PM nickel-based superalloy component was produced by direct forging of encapsulated powder on a single acting hydraulic press. A finite element model for the direct powder forging process has been developed in DEFORM-2D/3D and validated by comparing the experimental and simulated loading curve. The relation of stress and strain state with densification and recrystallisation nucleation degree has been analysed. The following conclusions can be drawn:

1. Direct powder forging, with a tool setup based on an extrusion cylinder and an ordinary single-acting hydraulic machine, can produce powder components with full density. The actual forging time was only $2.1 \mathrm{~s}$.

2. Compared with HIP process, the material produced by direct powder forging has a substantially higher recystallisation nucleation degree and recrystallised subgrains.

3. Within the forged component, a higher recystallisation nucleation degree resides in the material near the container wall. In general, material that had higher recrystallisation nucleation degree also had greater values of shear strain rate $\left(>0.01 \mathrm{~s}^{-1}\right)$.

4. A finite element model for the direct powder forging of FGH96 alloy has been developed in DEFORM-2D/3D and the simulated downward load agrees very well with the experimentally measured force. The model is able to predict the evolution of the relative density and its distribution during the forging process.

Acknowledgments Much appreciated is the strong support received from AVIC Beijing Institute of Aeronautical Materials (BIAM). The research was performed at the AVIC Centre for Materials Characterisation, Processing and Modelling at Imperial College London. Thanks are also due to Mr Longqi Zhao of Design \& Research Institute of Wuhan Iron \& Steel Group and Dr Feng-E Cui of University of Science \& Technology Beijing, for their help during thermal analysis and EBSD analysis. 
Open Access This article is distributed under the terms of the Creative Commons Attribution 4.0 International License (http:// creativecommons.org/licenses/by/4.0/), which permits unrestricted use, distribution, and reproduction in any medium, provided you give appropriate credit to the original author(s) and the source, provide a link to the Creative Commons license, and indicate if changes were made.

\section{References}

1. Viswanathan GB, Sarosi PM, Whitis DH, Mills MJ (2005) Deformation mechanisms at intermediate creep temperatures in the Ni-base superalloy Rene 88DT. Mater Sci Eng A 400-401: 489-495

2. Menon MN, Gurney FJ (1976) Microstructural investigation of the growth of large grains in prealloyed powder extrusions of a nickel base superalloy. Metall Trans A 7:731-743

3. Song K, Aindow M (2008) Grain growth and particle pinning in a model Ni-based superalloy. Mater Sci Eng A 479:365-372

4. Qiu QL, Attallah MM, Wu XH, Andrews P (2013) Influence of hot isostatic pressing temperature on microstructure and tensile properties of a nickel-based superalloy powder. Mater Sci Eng A 564: 176-185

5. Galindo-Nava EI, Rae CMF (2015) Microstructure evolution during dynamic recrystallisation in polycrystalline nickel superalloy. Mater Sci Eng A 636:434-445

6. Holm EA, Miodownik MA, Rollett AD (2003) On abnormal subgrain growth and the origin of recrystallisation nuclei. Acta Mater 51:2701-2716

7. Lafer M, Bouvard D, Stulz P, Pierronnet M, Raisson G (1992) Densification behaviour of particle-reinforced superalloy powder during hot isostatic pressing. In: Koizumi M (ed) Hot Isostatic Pressing - Theory and Application. Ryukoku University, Japan, pp 209-214

8. Immarigeon JPA, Floyd PH (1981) Microstructural instabilities during superplastic forging of a nickel-base superalloy compact. Metall Trans A 12:1177-1186

9. Anderson MJ, McGuire K, Zante RC, Ion WJ, Rosochowski A, Brooks JW JW (2013) Identifying the dominant failure mode in the hot extrusion tooling used to forge nickel based superalloy. $\mathrm{J}$ Mater Process Technol 213:111-119

10. Zhang MJ, Li FG, Wang SY, Liu CY (2011) Effect of powder preparation technology on the Hot deformation behavior of HIPed P/M nickel-base superalloy FGH96. Mater Sci Eng A 528:4030 4039

11. Mignanelli PM, Jones NG, Perkins KM, Hardy MC, Stone HJ (2015) Microstructural evolution of a delta containing nickel-base superalloy during heat treatment and isothermal forging. Mater Sci Eng A 621:265-271

12. Jafarian F, Imaz Ciaran M, Umbrello D, Arrazola PJ, Filice L, Amirabadi H (2014) Finite element simulation of machining Inconel 718 alloy including microstructure changes. Int J Mech Sci 88:110-121

13. Appa Rao G, Srinivas M, Sarma DS (2006) Effect of oxygen content of powder on Microstructure and mechanical properties of hot isostatically pressed superalloy Inconel 718. Mater Sci Eng A 435436:84-99

14. Zhang L, Liu H, He X, Rafi-ud-din QX, Qin M, Li Z, Zhang G (2012) Thermal evolution behavior of carbides and $\gamma^{\prime}$ precipitates in FGH96 superalloy powder. Mater Charact 67:52-64

15. Bai Q, Lin J, Tian G, Zou J, Dean TA (2015) Review and analysis of powder prior boundary (ppb) formation in powder metallurgy processes for nickel-based super alloys. J Powder Metall Min 4: 127. doi:10.4172/2168-9806.1000127

16. Gessinger GH, Cooper PD (1975) Effect of deformation on mechanical properties of high temperature P/M steel. Mater Sci Eng 18:249-254

17. Bai Q, Lin J, Jiang J, Dean TA, Zou J, Tian G (2015) A study of direct forging process for powder superalloys. Mater Sci Eng A 621:68-75

18. Bai Q, Lin J, Tian G, Balint DS, Zou J (2014) A novel forming process for powder metallurgy of superalloys. Key Eng Mater 622623:833-839

19. Tu WJ, Pollock TM (2010) Deformation and strain storage mechanisms during high-temperature compression of a powder metallurgy nickel-base superalloy. Metall Mater Trans A 41:2002-2009

20. Tsvhopp MA, Bartha BB, Porter WJ, Murray PT, Fairchild SB (2009) Microstructure-dependent local strain behavior in polycrystals through in-situ scanning electron microscope tensile experiments. Metall Mater Trans A 40:2363-2368

21. Ma Q, Lin Z, Yu Z (2009) Prediction of deformation behavior and microstructure evolution in heavy forging by FEM. Int J Adv Manuf Technol 40:253-260

22. Svyetlichnyy D, Nowak J, Nikolay Biba N, Łach Ł (2016) Flow stress models for deformation under varying condition - finite element method simulation. Int J Adv Manuf Technol. doi:10.1007/ s00170-016-8506-7

23. Lin YC, Li KK, Li HG, Chen J, Chen XM, Wen DX (2015) New constitutive model for high-temperature deformation behavior of Inconel 718 superalloy. Mater Des 74:108-118

24. Zhang Y, Chen ZT (2007) On the effect of stress triaxiality on void coalescence. Int J Fract 143:105-112

25. Vadillo G, Fernández-Sáez J (2009) An analysis of Gurson model with parameters dependent on triaxiality based on unitary cells. Eur J Mech A Solids 28:417-427

26. Kim J, Gao X, Srivatsan TS (2004) Modeling of void growth in ductile solids: effects of stress triaxiality and initial porosity. Eng Fract Mech 71:379-400

27. Hu CY, Liu XL, Chen X, Tao CH (2014) Failure analysis of rotating shaft in main undercarriage. Acta Aeronaut Astronautica Sinca 35: 461-468

28. Wei ZW, Liu CK, Gu YL, Tao CH (2015) Mechanical properties and fracture characteristics of welded joint in GH536 Ni-based superalloy. J Aeronaut Mater 35:70-74

29. Park CS, Na TW, Park HK, Lee BJ, Han CH, Hwang NM (2012) Three-dimensional Monte Carlo simulation for the effect of precipitates and sub-boundaries on abnormal grain growth. Scr Mater 66: 398-401

30. Ferry M, Humphreys FJ (2006) Onset of abnormal subgrain growth in cold rolled $\{110\}<001>$ oriented copper single crystals. Mater Sci Eng A 435-436:447-452

31. Zhang H, Zhang K, Zhou H, Lu Z, Zhao C, Yang X (2015) Effect of strain rate on microstructure evolution of a nickel-based superalloy during hot deformation. Mater Des 80:51-62

32. Tian LX, Ma CL (2015) Strain rate dependence of the yield stress and strain hardening rate of a single crystal superalloy at intermediate temperature. Mater Sci Eng A 620:198-203

33. Djavanroodi F, Omranpour B, Ebrahimi M, Sedighi M (2012) Designing of ECAP parameters based on strain distribution uniformity. Progress in Natural Science. Mater Int 22(5):452-460

34. EI-Danaf EA, Soliman MS, Almajid AA (2010) Effect of deformation path change on plastic response and texture evolution for 1050 Al pre-deformed by ECAP and subsequently plane strain compressed. Mater Sci Eng A 527:2547-2558 